\title{
Parallel Association of Shunt Active Power Filters
}

\author{
R. Pregitzer, J. G. Pinto, M. João Sepúlveda, João L. Afonso \\ Department of Industrial Electronics \\ University of Minho \\ Guimarães, Portugal \\ Email: \{rpregitzer|gpinto|mjs|jla\}@dei.uminho.pt
}

\begin{abstract}
This paper describes different types of parallel association of Shunt Active Power Filters, presents computer simulation models developed in PSCAD ${ }^{\circledR} /$ EMTDC $^{\mathrm{TM}}$, and shows simulated results for each case. The control system used in the active filters is based on the Instantaneous Reactive Power Theory (p-q Theory). The active filters use periodic sampling as switching technique. Two types of parallel associations are presented: two active filters in different parallel feeders; and both active filters connected in parallel at the same point of the electric installation. The paper also proposes a control strategy to solve an inherent operation problem that occurs in the second type of parallel association.
\end{abstract}

Keywords-Shunt Active Power Filter, Parallel Association, Instantaneous Reactive Power Theory, Computer Simulations, PSCAD®/EMTDC ${ }^{\mathrm{TM}}$, Power Quality.

\section{INTRODUCTION}

The intensive use of power converters and other non-linear loads in industry and by consumers in general, is causing an increasing deterioration of the power systems voltage and current waveforms.

The presence of harmonics in the power lines results in greater power losses in distribution, interference problems in communication systems, failure of electronic equipments, among other problems. The main consequence is the reduction of productivity in many industries, and therefore, the issue of power quality delivered to the end consumers is, more than ever, an object of great concern.

International standards concerning electrical power quality (IEEE-519, IEC 61000, EN 50160, among others) impose that electrical equipments and facilities should not produce harmonic contents greater than specified values, and also specify distortion limits to the supply voltage. Meanwhile, it is mandatory to solve the harmonic problems caused by the equipments already installed.

One of the modern solutions for solving problems related to the currents waveforms is the Shunt Active Filter. Depending on the control theory and the inverter topology, these active filters are capable of compensating harmonic currents, power factor and unbalance, achieving balanced, sinusoidal currents at the source, with an unitary value of power factor.

However, it is possible that in some cases, a single Shunt Active Power Filter is not capable of fully compensating all the load currents problems, and therefore, it may be necessary to use more than one filter per installation. This article presents two different situations where more than one Shunt Active
Filter is used in the same electrical installation. In the first situation one active filter is used in each feeder. Another situation consists of having two active filters connected in parallel at the same point. This might be applied when a single Shunt Active Filter is not capable of compensating the current problems of a certain large non linear load, and thus, inserting another active filter in parallel to the first one becomes a possible solution.

The simulated Shunt Active Filters presented in this paper use a control system based on the Instantaneous Reactive Power Theory (p-q Theory) developed by Akagi et al. [1] and expanded to three-phase four-wire system by Aredes et al. [2]. The simulation model emulates a digital controller, in order to accurately simulate the processing delays, as well as the fixed point calculations, that are performed in a real Microcontroller/DSP, that is used in a laboratory prototype [3]. The Simulation Models are developed using the PSCAD®/EMTDCTM tool.

A summary involving the major topics of this paper is described as follows: the control theory used to determine the reference currents is detailed in Section II, the inverter used for generating the reference currents in a three-phase four-wire system are presented in Section III, and in Section IV are introduced simulation cases analyzed with the tool PSCAD ${ }^{\circledR} /$ EMTDC $^{\mathrm{TM}}$. The results obtained with both cases are then presented and studied in Section V. Finally, conclusions and suggestions for future works are presented in Section VI.

\section{CONTROL THEORY}

As mentioned in the Introduction, the control strategy is based on the p-q Theory expanded for three-phase four-wire systems. The first step consists in an algebraic transformation (Clarke transform) of the three-phase system voltages $v_{a}, v_{b}$ and $v_{c}$ and the load currents $i_{a}, i_{b}$, and $i_{c}$ from the $a-b-c$ coordinates to the $\alpha-\beta-0$ reference frame.

$$
T=\sqrt{2} / 3 \cdot\left[\begin{array}{ccc}
1 / \sqrt{2} & 1 / \sqrt{2} & 1 / \sqrt{2} \\
1 & -1 / 2 & -1 / 2 \\
0 & \sqrt{3} / 2 & -\sqrt{3} / 2
\end{array}\right]
$$




$$
\left[\begin{array}{l}
v_{0} \\
v_{\alpha} \\
v_{\beta}
\end{array}\right]=T \cdot\left[\begin{array}{l}
v_{a} \\
v_{b} \\
v_{c}
\end{array}\right] \quad\left[\begin{array}{l}
i_{0} \\
i_{\alpha} \\
i_{\beta}
\end{array}\right]=T \cdot\left[\begin{array}{l}
i_{a} \\
i_{b} \\
i_{c}
\end{array}\right]
$$

Then, the p-q theory components are calculated by applying the expressions (3-5), where $p$ is the instantaneous real power, $q$ is the instantaneous imaginary power (by definition) and $p_{0}$ is the instantaneous zero-sequence power.

$$
\begin{aligned}
& p=v_{\alpha} \cdot i_{\alpha}+v_{\beta} \cdot i_{\beta} \\
& q=v_{\beta} \cdot i_{\alpha}-v_{\alpha} \cdot i_{\beta} \\
& p_{0}=v_{0} \cdot i_{0}
\end{aligned}
$$

Ideally, the source currents should only supply the average value of the instantaneous power $p$, which corresponds to the energy per time unit transferred from the source to the load, in a balanced way through the 3 phases, meaning that the active filter should supply the load with all the remaining instantaneous power components.

In addition to the instantaneous power components defined by the $\mathrm{p}-\mathrm{q}$ Theory, there is also a component, $p_{\text {reg }}$, which is used to regulate the capacitor voltage in the dc side of the Shunt Active Power Filter. This regulation is done with a proportional controller with a quadratic error between the reference voltage, $V_{r e f}$, and the voltage at the terminals of the capacitor bank, $V_{D C}$.

$$
p_{\text {reg }}=k_{p}\left(V_{r e f}^{2}-V_{D C}^{2}\right)
$$

The instantaneous powers that will be injected by the Shunt Active Filter, $p_{x}$ and $q_{x}$, are composed by the undesired power components, which are responsible for the harmonic currents, current unbalance and reactive power). The average value of the zero sequence instantaneous power $p_{0}$ and $p_{\text {reg }}$ are introduced with an opposite signal because they must be drained from the source in order to keep the source currents balanced and the dc voltage regulated, respectively.

$$
\begin{aligned}
& p_{x}=\tilde{p}-\bar{p}_{0}-p_{\text {reg }} \\
& q_{x}=q
\end{aligned}
$$

Finally, it is possible to calculate the compensation reference currents $i_{c a}, i_{c b}$, and $i_{c c}$ in the $\alpha-\beta-0$ coordinates, by using the expressions (9) and (10). The reference currents are then translated to the $a-b-c$ reference frame through the inverse Clarke transform.

$$
\begin{aligned}
& {\left[\begin{array}{l}
i_{c \alpha} \\
i_{c \beta}
\end{array}\right]=\frac{1}{v_{\alpha}^{2}+v_{\beta}^{2}} \cdot\left[\begin{array}{cc}
v_{\alpha} & v_{\beta} \\
-v_{\beta} & v_{\alpha}
\end{array}\right] \cdot\left[\begin{array}{l}
p_{x} \\
q_{x}
\end{array}\right]} \\
& i_{c 0}=i_{0}=\frac{1}{\sqrt{3}} \cdot\left(i_{a}+i_{b}+i_{c}\right)
\end{aligned}
$$

\section{INVERTER TOPOLOGY}

The inverter of each Shunt Active Filter is a two level, four legs Voltage Source Inverter (VSI) using IGBTs. In order to connect the inverter to the electric grid inductors $(L)$ are used in series with each leg. Passive low-pass filters with a cutoff frequency of approximately $4 \mathrm{kHz}$ are then applied to filter out the noise produced by the IGBTs switching. The dc-link uses a $1.5 \mathrm{mF}$ capacitor bank.

Fig. 1 shows the full inverter schematic connected to the electric grid.

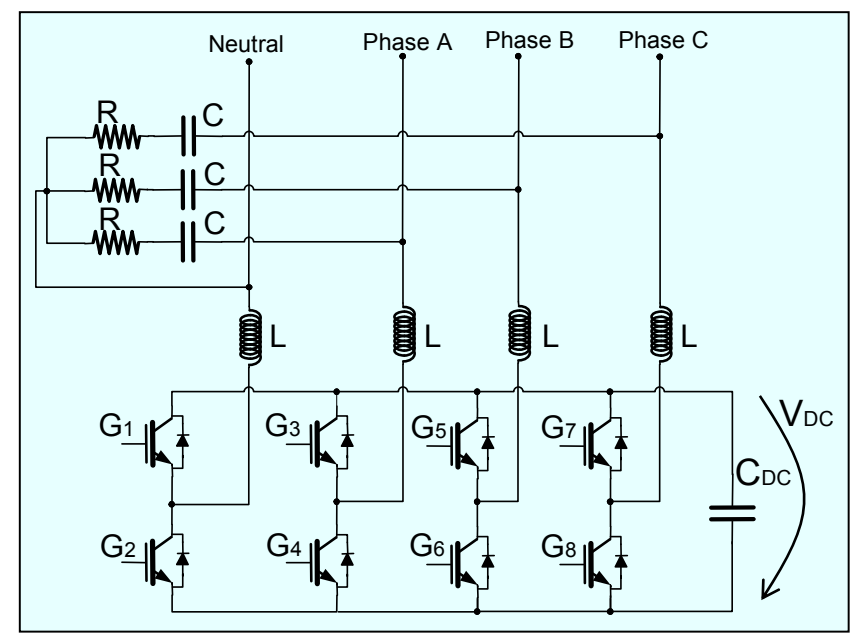

Fig. 1. Two level four legs inverter

\section{SimUlATION DESCRIPTION}

The simulation models were developed using the PSCAD®/EMTDCTM v4.2 tool. The controller and hardware were modeled according to a laboratory prototype, as described in [3]. In short, many of the limitations of a fixed-point Digital Signal Processor (DSP) were taken into consideration, like processing delays, and errors introduced by fixed point calculations, among other details that increase simulation accuracy.

In order to improve the performance of the control system, the calculation of the average values of $p$ and $p_{0}$ were made using sliding windows that take advantage of the symmetries existing in the instantaneous powers [4], and a block for compensating processing delays was also used.

To test different types of parallel association of Shunt Active Power Filters, two simulation cases were developed: the first case presents two active filters in different parallel feeders, and is illustrated in Fig.2; the second case has two active filters connected in parallel at the same point of the electrical installation, and is shown in Fig. 3.

In the first case, the "Active Power Filter 1" is compensating a full bridge rectifier with a parallel $\mathrm{RC}$ branch on the dc side. This load consumes an apparent power of $19 \mathrm{kVA}$. As for the other active filter, it is compensating a full bridge rectifier with a series $\mathrm{RL}$ branch on the dc side requires $23 \mathrm{kVA}$ 


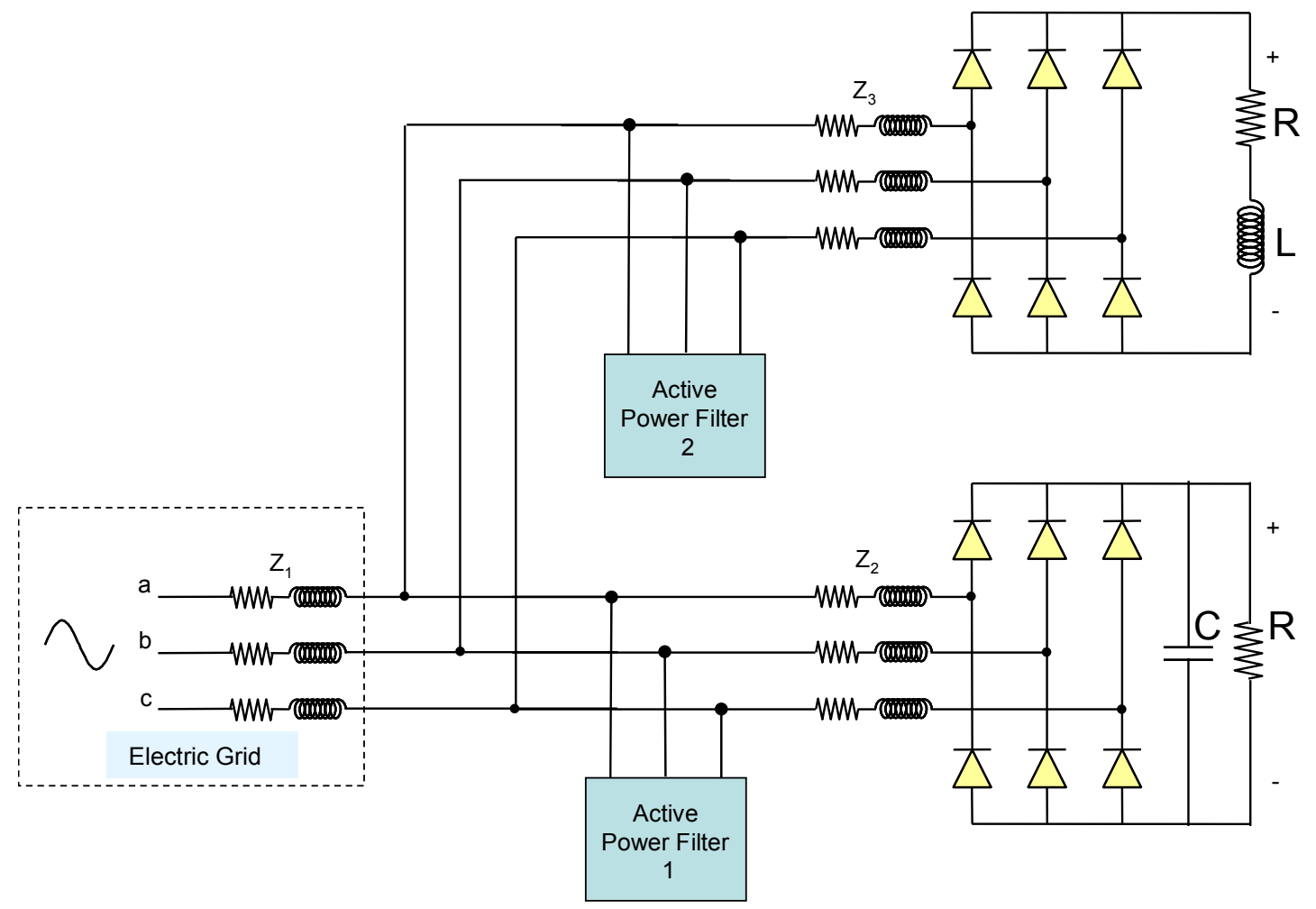

Fig.2. Two Shunt Active Power Filters connected in different parallel feeders

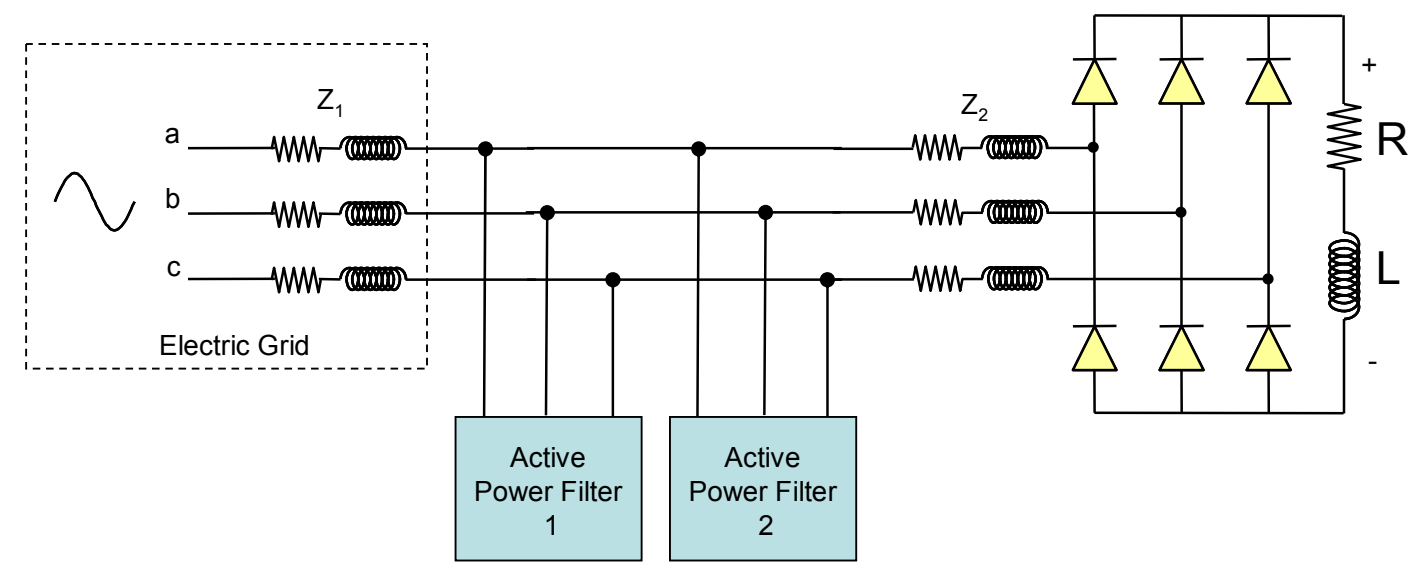

Fig.3. Two Shunt Active Power Filters connected at the same point

In the second case a $53 \mathrm{kVA}$ diode bridge rectifier with a series RL branch was used. The line impedances are as follows:

TABLE I

LINE IMPEDANCE CHARACTERISTICS

\begin{tabular}{|c|c|c|}
\hline & $\mathrm{R}$ & $\mathrm{L}$ \\
\hline $\mathrm{Z}_{1}$ & $0,05 \Omega$ & $385 \mu \mathrm{H}$ \\
\hline$Z_{2}$ & $0,1 \Omega$ & $50 \mu \mathrm{H}$ \\
\hline$Z_{3}$ & 0,15 & $60 \mu \mathrm{H}$ \\
\hline
\end{tabular}

The second simulation case requires an adaptation of the active filters control theory. The power components to be compensated assume values that are only a part of the total values calculated for the load. If the active filters are equal (that is not a necessary condition), each one of them will correct only half of the load power components, as shown in $(11,12)$. The value of the power component, $p_{\text {reg }}$, used to regulate the capacitor voltage in the dc side of the active filter is not changed by this adaptation, as seen in (11), and therefore expression (6) is applied for each dc link. 


$$
\begin{aligned}
& p_{x_{-} n}=\tilde{p} / 2-\bar{p}_{0} / 2-p_{\text {reg_n }} \\
& q_{x_{-} n}=\frac{4}{2}
\end{aligned}
$$

Where the subscript parameter $n$ assumes the values 1 or 2 , respectively for the Shunt Active Filters 1 and 2.

After calculating the instantaneous compensation power components it is only necessary to determine the reference currents for each inverter, according to $(9,10)$ and using the inverse Clarke transform of (1).

\section{Simulation Results}

This item presents the simulation results obtained for the two different association types of shunt active filters.

\section{A. Two Shunt Active Filters in Different Parallel Feeders}

Fig. 4 shows the system voltages and Fig. 5 shows the load currents of the electric system, when both filters are offline.

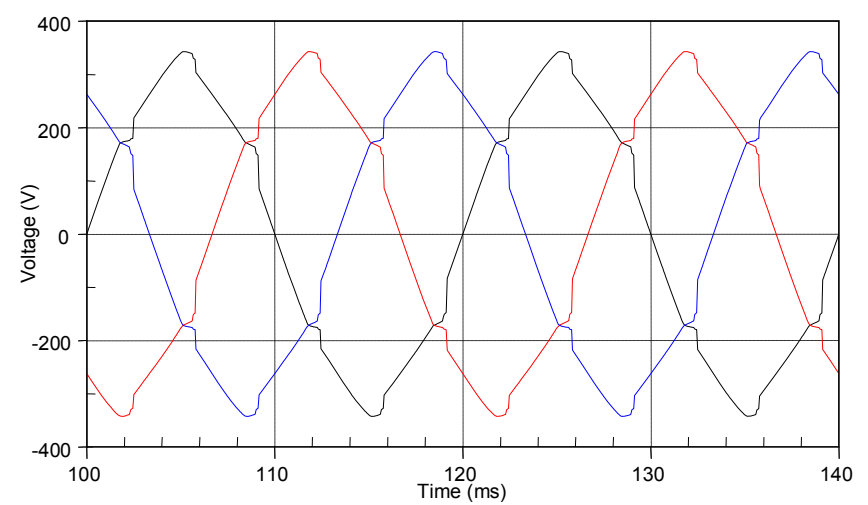

Fig. 4. Initial system voltages (with active filters off)

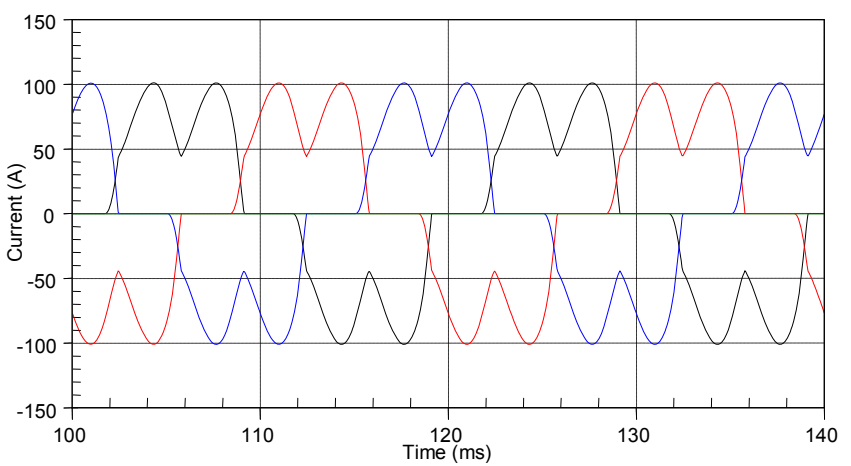

Fig. 5. Initial source currents (with active filters off)

The voltages have a THD of $6.9 \%$ and the load currents have a THD of $36 \%$ (51 harmonics were taken into consideration for the THD calculation).

When both filters are connected the source currents are compensated and become practically sinusoidal and with unitary power factor. Fig. 6 and 7 show the system voltages and the source currents after compensation. The current THD becomes $4.2 \%$ and the voltage THD drops to $2.1 \%$.

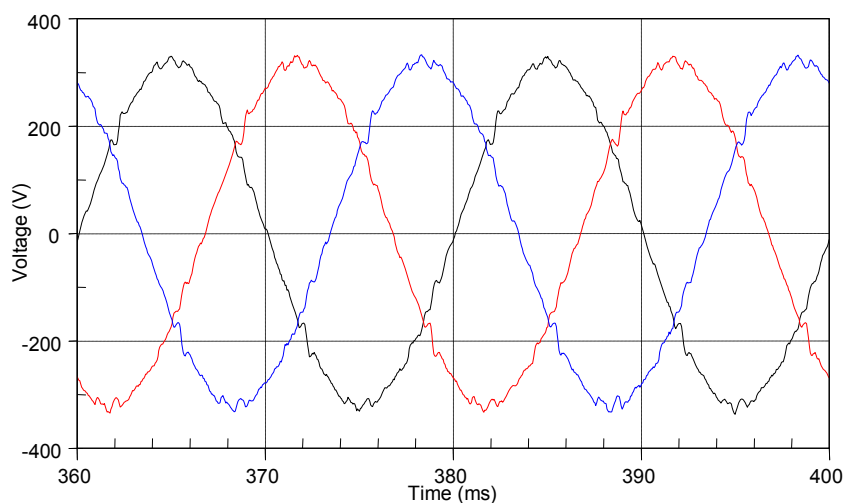

Fig. 6. Final system voltages (with active filters on)

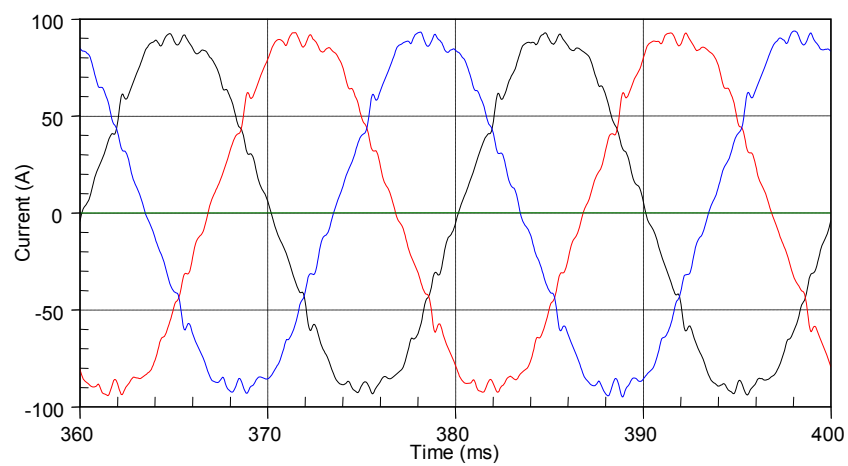

Fig. 7. Final source currents (with active filters on)

In Fig. 8 and Fig. 9 it is possible to see the dc-link voltages for both active filters. The dc-link voltage of the active filter that compensates the diode bridge rectifier with the RC load requires a higher voltage because current variations are higher. This voltage could be significantly lower if another switching technique would be used [5].

It should be taken into consideration, that for these simulations no soft start was considered for the charging of the dc link capacitors of the active filters.

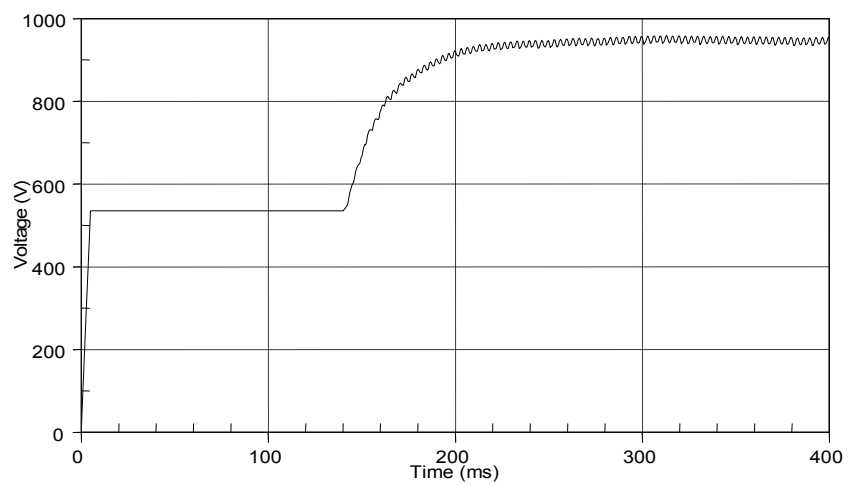

Fig. 8. Capacitor voltage at the dc-link of the active filter 1 


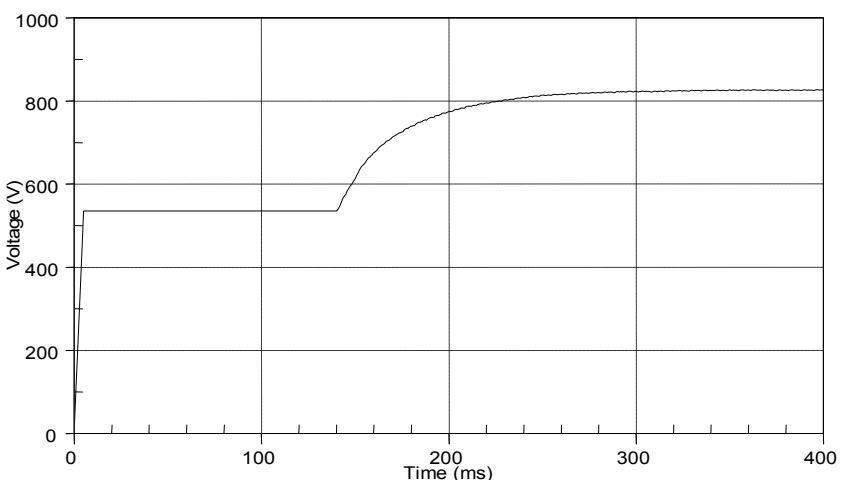

Fig. 9. Capacitor voltage at the dc-link of the active filter 2

\section{B. Two Shunt Active Filters Connected at the Same Point}

In this case both active filters compensate the same load. Before testing the shunt active filters with the load shown in Fig. 3, an experience was carried out to discover if the active filters turning on sequence affects the system performance. Two turn-on sequences were considered: turn on the first filter, wait for system stability, then turn on the second filter; and turn on the two active filters simultaneously. In this experience a linear $\mathrm{RL}$ load was used $(\mathrm{R}=7 \Omega, \mathrm{L}=10 \mu \mathrm{H})$. In Fig. 10 it is possible to see the source currents when the first shunt active filter was connected at $80 \mathrm{~ms}$, and when the second one was turned on at $120 \mathrm{~ms}$. Fig. 11 presents the source currents when both active filters are connected simultaneously at $80 \mathrm{~ms}$.

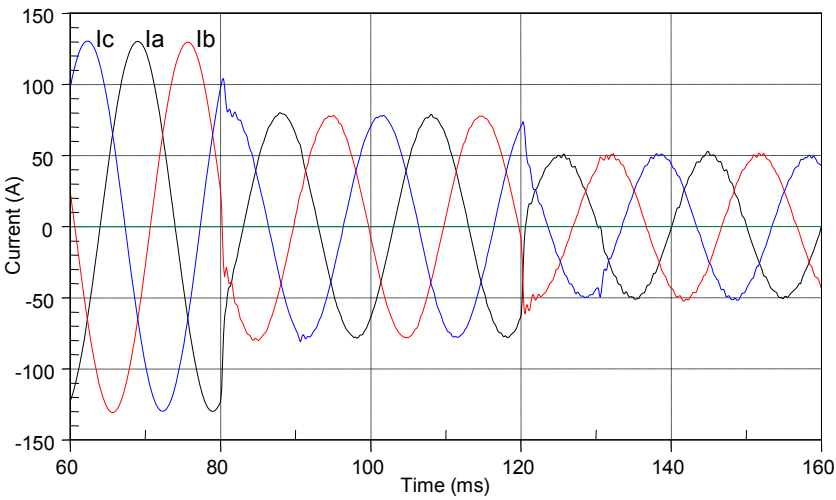

Fig. 10. Source currents (active power filters connected separately)

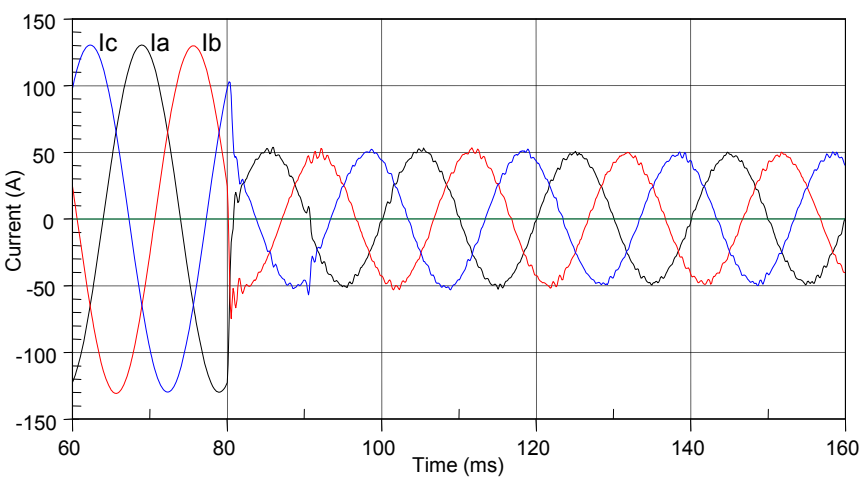

Fig. 11. Source currents (active power filters connected simultaneously)

As it can be observed (Fig. 10 and Fig. 11) there is no advantage in separately turning on the shunt active filters. Therefore, in the next simulations the active filters are connected simultaneously. In this case, both active filters compensate the same load, which consists in a three-phase diode bridge rectifier with RL load in the de side. The voltage and current waveforms before turning on the active filters are shown in Fig. 12 and Fig. 13, respectively. The voltage THD is $7.2 \%$ and the current has an harmonic content of $26 \%$.

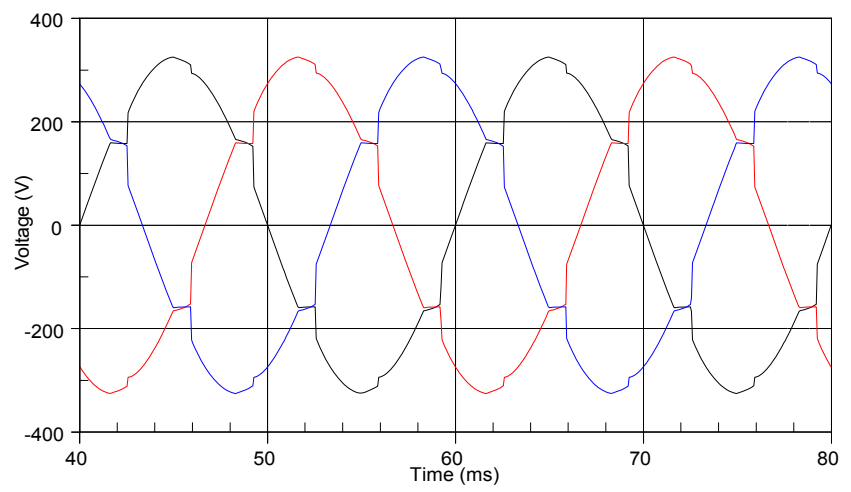

Fig. 12. Initial system voltages (with active filters off)

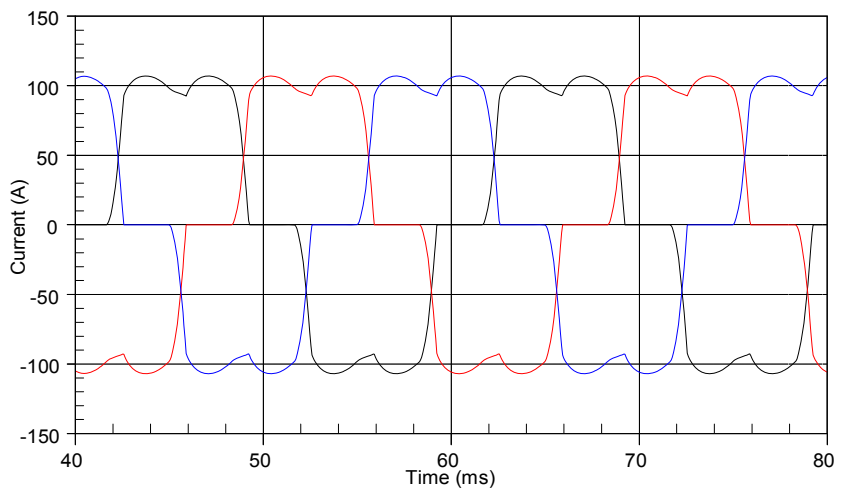

Fig. 13. Initial source currents (with active filters off)

When the shunt active filters are connected the THD and power factor are compensated. The THD of the voltages (Fig. 14) is reduced to $1.7 \%$, and the THD of the source currents (Fig. 15) becomes 2.5\%.

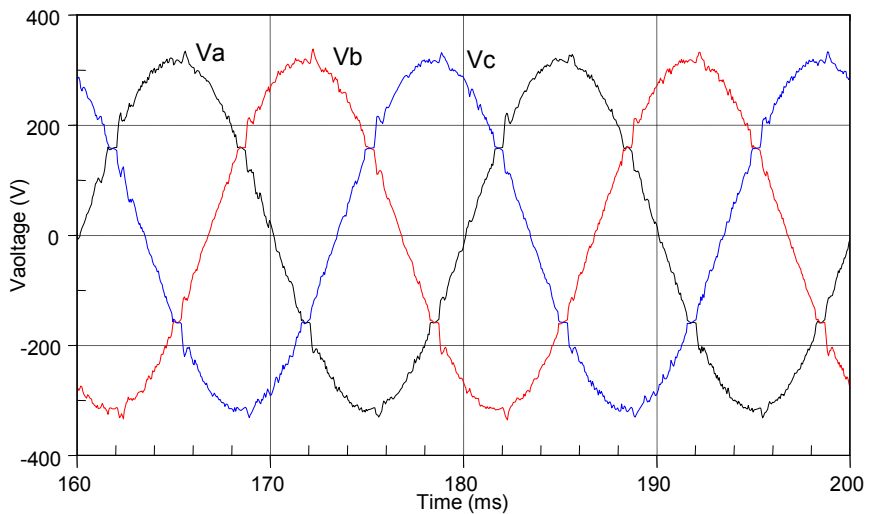

Fig. 14. Final system voltages (with active filters on) 


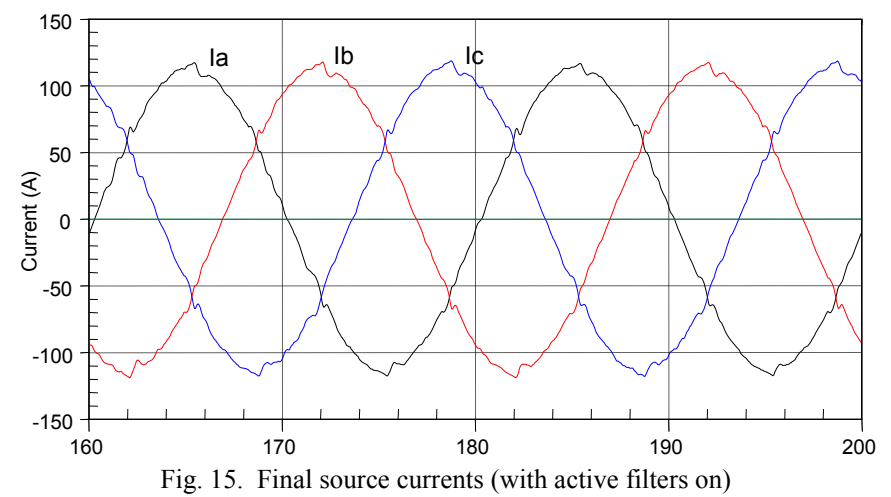

The dc-link voltages of both inverters can be seen in Fig. 16 and Fig. 17. It is possible to see that these voltages present identical behavior, with no problems at all. It should be taken into account that the filters started compensating the load after a pre-charge of $800 \mathrm{~V}$, without any soft start for simplicity.

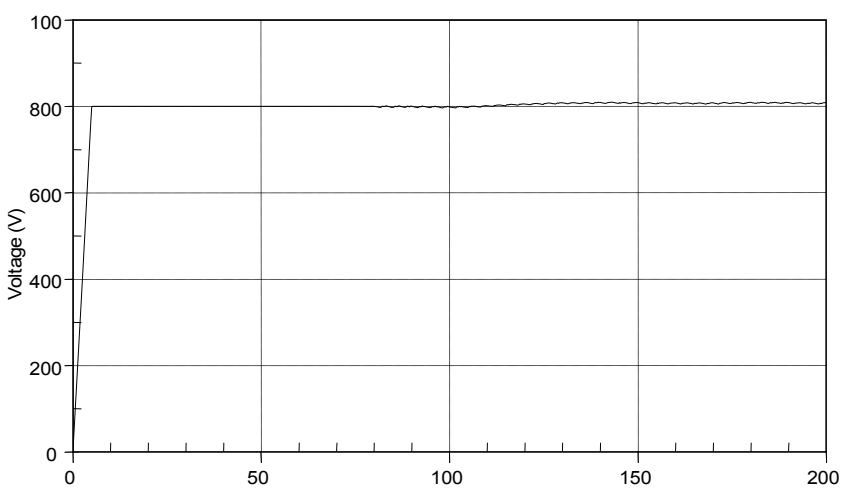

Fig. 16. Capacitor voltage at the dc-link of the active filter 1

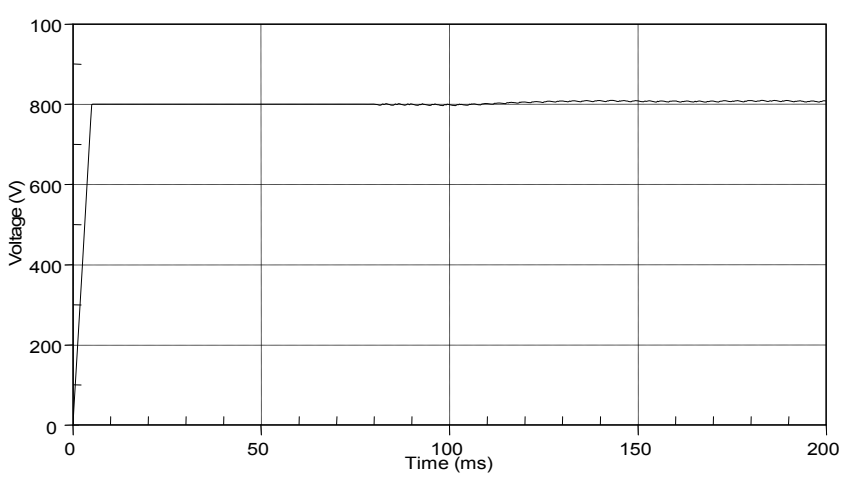

Fig. 17. Capacitor voltage at the dc-link of the active filter 2

\section{CONCLUSIONS AND FUTURE WORKS}

This paper shows that it is possible to associate Shunt Active Power Filters in parallel in order to compensate currents on a given electric installation. This solution may be necessary when a single active filter does not have enough power to compensate the current problems in a satisfactory way, and it is chosen to keep the existing active filter, instead of just replacing it for a higher power one.

It is shown that when the Shunt Active Filters are on different feeders, no adaptation of the control system is necessary, however when both active filters are connected at the same point minor adjustments are required so that each filter compensates part of the problems.

In the future, other configurations will also be analysed, and the switching technique will be changed to assure fixed frequency, in order to see if the impact of having more than one active filter operating in parallel in an installation is minimized.

\section{ACKNOWLEDGMENT}

This work was supported by FCT (Fundação para a Ciência e a Tecnologia), project funding POCTI/ESE/41170/2001 and POCTI/ESE/48242/2002. The authors are also grateful to PRIME (Programa de Incentivos à Modernização da Economia) for funding the Project SINUS.

\section{REFERENCES}

[1] H. Akagi, Y. Kanazawa, A. Xabae, "Generalized Theory of the Instantaneous Reactive Power in Three-phase Circuits", IPEC'83 - Int. Power Electronics Conference; Tokyo, Japan; 1983; pp. 1375-1386.

[2] M. Aredes; E. H. Watanabe; "New Control Algorithms for Series and Shunt Three-Phase Four-Wire Active Power Filters"; IEEE Transactions on Power Delivery, vol. 10, no. 3, Jul. 1995; pp.: 1649 - 1656.

[3] R. Pregitzer, J.C. Costa, Júlio S. Martins, J. L . Afonso, "Simulation and Implementation Results of a 3 Phase 4 Wire Shunt Active Power Filter", CDROM Proceedings of the ICHQP 2006 - International Conference on Harmonics and Quality of Power, Cascais, Portugal, 1-5 October 2006.

[4] J. L. Afonso; M. J. S. Freitas; J. S. Martins; p-q Theory Power Components Calculations; 2003 IEEE International Symposium on Industrial Electronics, ISIE '03, vol. 1, 9-11 Jun. 2003; pp.: 385 - 390.

[5] R. Pregitzer; Computer Simulations of Active Power Filters in Real Operating Conditions; MSc. Thesis (in Portuguese); Universidade do Minho; Portugal; September 2006. 